Polymer Journal, Vol. 39, No. 6, pp. 543-550 (2007)

(C) 2007 The Society of Polymer Science, Japan

\title{
Synthesis and Characterization of High Refractive Index Polyimides Derived from 4,4'-( $p$-Phenylenedisulfanyl)dianiline and Various Aromatic Tetracarboxylic Dianhydrides
}

\author{
Jin-gang LiU, Yasuhiro NAKamura, Yuji Shibasaki, Shinji Ando, and Mitsuru UedA ${ }^{\dagger}$ \\ Department of Organic and Polymeric Materials, Tokyo Institute of Technology, \\ 2-12-1-H120, O-okayama, Meguro-ku, Tokyo 152-8552, Japan
}

(Received February 7, 2007; Accepted March 6, 2007; Published April 17, 2007)

\begin{abstract}
A series of sulfur-containing polyimides with high refractive indices have been synthesized from an aromatic sulfur-containing diamine, 4,4'-( $p$-phenylenedisulfanyl)dianiline (2SPDA) and various aromatic tetracarboxylic dianhydrides via a two-step polycondensation procedure. 2SPDA was synthesized by the Williamson reaction of 4aminothiophenol with 1,4-dichlorobenzene in a yield of 75.8\%. The flexible and tough polyimide films exhibited good thermal stability with the glass transition temperatures of $214.6-261.6^{\circ} \mathrm{C}$, the $5 \%$ weight loss temperatures of 509 $537^{\circ} \mathrm{C}$, and residual weights of $83-91 \%$ at $550{ }^{\circ} \mathrm{C}$ in nitrogen. The films also exhibited the good transmittances of higher than $80 \%$ at $500 \mathrm{~nm}$. The average refractive indices $\left(n_{\text {av }}\right)$ and in-plane/out-of-plane birefringence $(\Delta n)$ measured at $632.8 \mathrm{~nm}$ are in the range of $1.7117-1.7356$ and $0.0074-0.0119$, respectively. The good transparency in the visible region, high $n_{\text {av }}$, and low $\Delta n$ of the PI films are very suitable for optical applications. [doi:10.1295/polymj.PJ2006232] KEY WORDS Sulfur-Containing Polyimide / High Refractive Index / Transparency / Thermal Stability /
\end{abstract}

Aromatic polyimides (PIs), known for their excellent physical and chemical properties, have been researched and developed for many years from both of the academic and technical interests. ${ }^{1,2}$ Recently, much attention has been paid to the applications of PIs in optical devices, including optical waveguides, anti-reflection films, lens, optical image sensors, and so on. ${ }^{3-6}$ The most widely studied PIs for optical applications are fluorinated ones, which exhibit the good processability, thermal stability, low dielectric constants and refractive indices, combined with good transparency in the visible region as well as at the near infrared wavelengths for telecommunication $(1.3 \mu \mathrm{m}$ and $1.55 \mu \mathrm{m}) .^{7-9}$ Although a variety of PIs for optical applications have been reported, sulfur-containing polyimides have rarely been introduced. ${ }^{10,11}$ In fact, sulfur-containing polymers, such as poly(methacrylates), ${ }^{12-14}$ epoxy, ${ }^{15}$ and polyurethane, ${ }^{16,17}$ have been used for plastic lens, films and optical components. Conventional sulfur-containing polymers afford high transparency, high refractive indices, and good adhesion, although the thermal stability of the polymers was often limited owing to their intrinsic thermalunstable structures. Recently, high refractive index PI coatings with high thermal stability have been proposed for optoelectronic applications, such as charge coupled device (CCD) image sensors, complementary metal oxide semiconductor (CMOS) image sensors, and so on. ${ }^{18-20}$ However, up to now, the high refractive index values obtained in the literatures have mainly been achieved by incorporation with metal oxide compounds, such as titanium dioxide or zirconium oxide. ${ }^{18}$ To our knowledge, few works have been reported to develop PIs with inherent high refractive index up to now. Thus, it is a challenging project to combine the high thermal stability of PIs with the high refractive indices of sulfur substituents, thus to afford new optical materials with good combined properties.

In the present work, we report a series of sulfurcontaining PIs with the high refractive indices from an aromatic sulfur-containing diamine, $4,4^{\prime}$ - $(p$-phenylenedisulfanyl)dianiline (2SPDA) and three aromatic tetracarboxylic dianhydrides. The flexible thioether moieties in the PIs, on one hand, provide them the high refractive indices and low birefringences, and on the other hand, good film-forming properties, optical transparency, and good mechanical properties. Although the glass transition temperatures of the PIs decrease due to the existence of flexible thioether linkages, they are high enough to meet the needs of optical devices fabrications.

\section{EXPERIMENTAL}

\section{Materials}

p-Aminothiophenol (Aldrich, Japan) and 1,4-dichlorobenzene (TCI, Japan) were purchased and used as received. 3,3',4,4'-Biphenyltetracarboxylic dianhydride (symmetric BPDA, sBPDA, TCI, Japan) and 4,4'-oxydiphthalic anhydride (ODPA, TCI, Japan)

${ }^{\dagger}$ To whom correspondence should be addressed (Tel/Fax: +81-3-5734-2127, E-mail: ueda.m.ad@m.titech.ac.jp). 
were dried at $160^{\circ} \mathrm{C}$ overnight in vacuo prior to use. 2,3,3',4'-Biphenyltetracarboxylic dianhydride (asymmetric BPDA, aBPDA) was synthesized in-house according to a modified reported procedure. ${ }^{21}$ Commercially available $N$-methyl-2-pyrrolidinone (NMP) and $N, N$-dimethylformamide (DMF) were purified by vacuum distillation over $\mathrm{CaH}_{2}$ prior to use.

\section{Measurements}

Inherent viscosity was measured using an Ubbelohde-viscometer with a $0.5 \mathrm{~g} / \mathrm{dL}$ NMP solution at $30{ }^{\circ} \mathrm{C}$. ${ }^{1} \mathrm{H}$ and ${ }^{13} \mathrm{C}$ NMR spectra were recorded on a Bruker DPX300 spectrometer using DMSO- $d_{6}$ as the solvent and tetramethylsilane as the reference. Fourier transform infrared (FT-IR) spectra were obtained with a Horiba FT-720 Fourier transform spectrophotometer. Ultraviolet-visible (UV-Vis) spectra were recorded on a JASCO V-560 spectrophotometer at room temperature. PI films were dried at $100^{\circ} \mathrm{C}$ for $1 \mathrm{~h}$ prior to test to remove the absorbed moisture. The wideangle X-ray diffraction (XRD) was conducted on a Rigaku D/max-2500 X-ray diffractometer with $\mathrm{Cu} /$ $\mathrm{K}-\alpha 1$ radiation, operated at $40 \mathrm{kV}$ and $200 \mathrm{~mA}$. Thermogravimetric analysis (TGA) was recorded on a Seiko TG/DTA 6300 thermal analysis system at a heating rate of $10^{\circ} \mathrm{C} / \mathrm{min}$ in nitrogen. Differential scanning calorimetry (DSC) was performed on a Seiko DSC 6300 at a heating rate of $10^{\circ} \mathrm{C} / \mathrm{min}$ in nitrogen. Dynamic mechanical thermal analysis (DMA) was performed on PI film specimens (30 mm long, $10 \mathrm{~mm}$ wide, and $50-60 \mu \mathrm{m}$ thick) on a Seiko DMS 6300 at a heating rate of $2{ }^{\circ} \mathrm{C} / \mathrm{min}$ with a load frequency of $1 \mathrm{~Hz}$ in air. The glass transition temperatures $\left(T_{\mathrm{g}} \mathrm{s}\right)$ are determined as the peak temperatures of loss modulus $\left(E^{\prime \prime}\right)$ plots.

The out-of-plane $\left(n_{\mathrm{TM}}\right)$ and in-plane $\left(n_{\mathrm{TE}}\right)$ refractive indices of PI films were measured with a prism coupler (Metricon, model PC-2000) equipped with a He-Ne laser light source (wavelength: $632.8 \mathrm{~nm}$ ). In plane/out-of-plane birefringence $(\Delta n)$ was calculated as a difference between $n_{\mathrm{TE}}$ and $n_{\mathrm{TM}}$. The average refractive index $\left(n_{\mathrm{av}}\right)$ was calculated according to eq 1:

$$
n_{\mathrm{AV}}=\sqrt{\left(2 n_{\mathrm{TE}}^{2}+n_{\mathrm{TM}}^{2}\right) / 3}
$$

\section{Calculations}

The DFT level of theory with the three-parameter Becke-style hybrid functional (B3LYP), which employs the Becke exchange and LYP correlation functions, was adopted for calculations of molecular polarizabilities in conjunction with the Gaussian basis sets. The 6-311G (d) basis set was used for geometry optimizations under no constraints, and the $6-311++G(d, p)$ was used for calculations of linear polarizabilities. ${ }^{22}$ All the calculations were performed using the software package of Gaussian-03 (Rev.C02 and D01).

Refractive index of compounds can be calculated using the Lorentz-Lorenz eq $2: 23,24$

$$
\frac{n^{2}-1}{n^{2}+2}=\frac{4 \pi}{3} \frac{\rho \cdot N_{\mathrm{A}}}{M_{\mathrm{w}}} \alpha=\frac{4 \pi}{3} \frac{\alpha}{V_{\mathrm{mol}}}
$$

where $n$ is the refractive index, $\rho$ the density, $N_{\mathrm{A}}$ the Avogadro number, $M_{\mathrm{w}}$ the molecular weight, $\alpha$ the linear molecular polarizability, and $V_{\text {mol }}$ the molecular volume. As shown in eq 2, molecular volume or density of materials is needed to calculate refractive index. However, such parameters are generally difficult to predict due to the difficulty in estimating the status of molecular packing. In contrast, van der Waals volumes $\left(V_{\mathrm{vdw}}\right)$ can be readily calculated from optimized geometries using the Slonimski's method, ${ }^{25}$ in which the van der Waals radii of atoms reported by Bondi are used. ${ }^{26}$ The molecular packing constant $K_{\mathrm{p}}$ defined as eq 3 can be used as a measure of molecular packing.

$$
K_{\mathrm{p}}=\frac{V_{\mathrm{vdw}}}{V_{\mathrm{mol}}}=\frac{\rho \cdot N_{\mathrm{A}}}{M_{\mathrm{w}}} V_{\mathrm{vdw}}
$$

The $V_{\text {mol }}$ of a certain molecule is the summation of $V_{\mathrm{vdw}}$ and intermolecular free spaces. For instance, dense molecular packing caused by intermolecular hydrogen bonds or charge transfer interactions, the values of $K_{\mathrm{p}}$ increase due to a decrease in the intermolecular spaces. In this study, a typical $K_{\mathrm{p}}$ value of 0.60 was used for prediction of refractive indices. ${ }^{27}$

\section{Monomer Synthesis}

Synthesis of 4,4'-(p-Phenylenedisulfanyl)dianiline (2SPDA). In a $250 \mathrm{~mL}$ three-necked flask equipped with a magnetic stirrer, a nitrogen inlet, a Dean-Stark trap, and a condenser was placed $p$-aminothiophenol $(25 \mathrm{~g}, 0.20 \mathrm{~mol})$, anhydrous $\mathrm{K}_{2} \mathrm{CO}_{3}(14.37 \mathrm{~g}, 0.104$ mol), distilled $N$-methyl-2-pyrrolidone $(48 \mathrm{~mL})$, and toluene $(50 \mathrm{~mL})$. The mixture was heated with stirring at $140{ }^{\circ} \mathrm{C}$ for $4 \mathrm{~h}$ in nitrogen to facilitate dehydration. After complete removal of the water, the residual toluene was distilled off. Then, the mixture was cooled to $120^{\circ} \mathrm{C}$, and 1,4-dichlorobenzene (11.76 g, $0.08 \mathrm{~mol})$ dissolved in NMP $(32 \mathrm{~mL})$ was added dropwise to the mixture. After addition, the reaction mixture was heated to $170{ }^{\circ} \mathrm{C}$ and maintained at this temperature for $12 \mathrm{~h}$. Then, the mixture was poured into cold water (1 L) to give a yellow precipitate. The solid was collected and washed thoroughly with water to give a crude product that was purified by recrystallization from ethanol. Yield: $24.6 \mathrm{~g}$ (75.8\%); $\mathrm{mp}: 164.9^{\circ} \mathrm{C}$ (DSC peak). FT-IR $\left(\mathrm{KBr}, \mathrm{cm}^{-1}\right)$ : 3417.2 , 3316.9, 1627.6, 1589.0, 1496.5, 1288.2, 
1172.5, 1095.4, 825.4. ${ }^{1} \mathrm{H}$ NMR (300 MHz, DMSO$\left.d_{6}, \mathrm{ppm}\right): 5.39(\mathrm{~s}, 4 \mathrm{H}), 6.60-6.63(\mathrm{~d}, 4 \mathrm{H}), 6.96-6.97$ (d, 4H), 7.13-7.16 (d, 4H). ${ }^{13} \mathrm{C}$ NMR $(300 \mathrm{MHz}$, DMSO- $\left.d_{6}, \mathrm{ppm}\right): 150.6,137.6,136.7,128.4,116.5$, 115.8. Elemental analysis: calculated for $\mathrm{C}_{18} \mathrm{H}_{16} \mathrm{~N}_{2} \mathrm{~S}_{2}$ : C, 66.63\%; H, 4.97\%; N, 8.63\%. Found: C, 66.42\%; $\mathrm{H}, 5.11 \% ; \mathrm{N}, 8.47 \%$.

\section{Polymer Synthesis}

Synthesis of PI-1 is described as a typical procedure. To a stirred solution of 2SPDA (1.6223 g, 5 mmol) in freshly-distilled NMP $(10 \mathrm{~mL})$, was added sBPDA $(1.4711 \mathrm{~g}, 5 \mathrm{mmol})$ in three portions under nitrogen. An additional NMP $(2.5 \mathrm{~mL})$ was added to wash the residual dianhydride, and at the same time to adjust the solid content of the reaction system to be $20 \mathrm{wt}$. \%. The reaction mixture was stirred at room temperature for $24 \mathrm{~h}$ to afford a viscous poly(amic acid) solution with an inherent viscosity of $1.17 \mathrm{dL} /$ $\mathrm{g}$, measured at a concentration of $0.5 \mathrm{~g} / \mathrm{dL}$ NMP solution at $30^{\circ} \mathrm{C}$. The pale-brown PAA solution was diluted to $10 \mathrm{wt} . \%$ and filtered through a $0.45 \mu \mathrm{m}$ Teflon syringe filter to eliminate any particulates that might affect the quality of the cured film. The purified PAA-1 solution was spin-coated on a silicon wafer, and the thickness was controlled by spin coating rate. For example, the thickness of a specimen for FT-IR and UV-Vis measurements was controlled to be about $10 \mu \mathrm{m}$, and the specimen for thermal properties measurement was adjusted to be $30-50 \mu \mathrm{m}$. The PI-1 film was obtained by thermal curing of PAA- 1 film in an oven for $1 \mathrm{~h}$ each at $80^{\circ} \mathrm{C}, 150^{\circ} \mathrm{C}, 250^{\circ} \mathrm{C}, 300^{\circ} \mathrm{C}$, respectively. The PI films were peeled by immersing the $\mathrm{Si}$ wafer in warm water.

PI-2 (aBPDA-2SPDA) and PI-3 (ODPA-2SPDA) films were obtained with the similar method as mentioned above. For optical measurements, purified PAA solutions were spin-coated on fused silica substrates ( $3 \mathrm{~mm}$-thick, 3 inch-radius), and the film thickness were controlled by spin coating to be $c a .10 \mu \mathrm{m}$. The PAA solutions were dried at $70^{\circ} \mathrm{C}$ for $30 \mathrm{~min}$, followed by thermal imidization at $280^{\circ} \mathrm{C}$ for $1 \mathrm{~h}$ under nitrogen flow. The heating rate to the imidization temperature was $5^{\circ} \mathrm{C} / \mathrm{min}$.

\section{RESULTS AND DISCUSSION}

\section{Synthesis of Diamines (2SPDA)}

It is well known that introduction of sulfur atoms into polymers significantly increase the refractive indices. To achieve this goal, a sulfur-containing new diamine, 2SPDA was prepared by the Williamson reaction of 4-aminothiophenol with 1,4-dichlorobenzene in a yield of more than $75 \%$ (Scheme 1). Figure 1 shows the FT-IR spectra of 2SPDA, in which

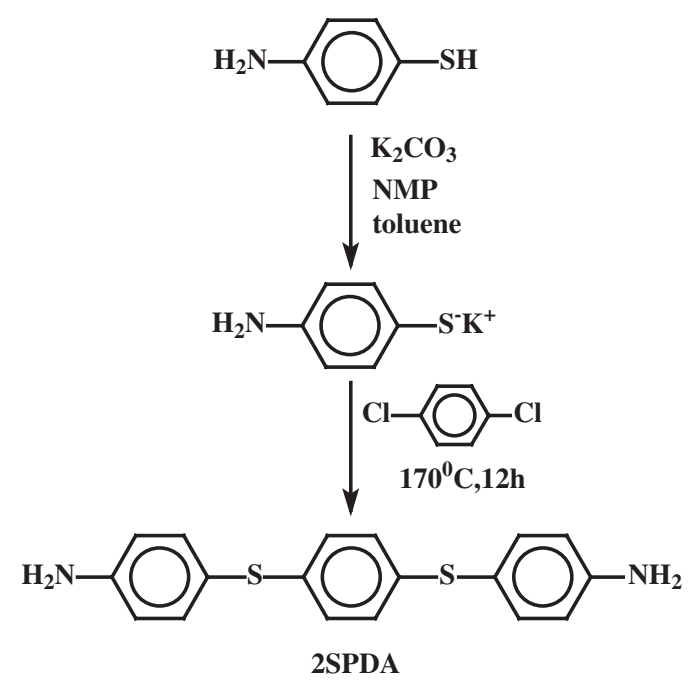

Scheme 1. Synthesis of 2SPDA.

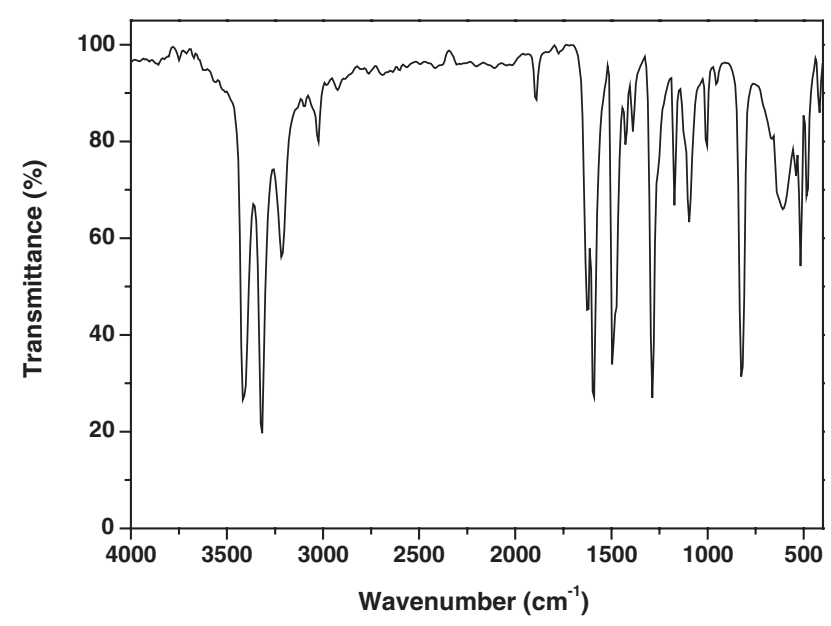

Figure 1. FT-IR spectra of 2SPDA ( $\mathrm{KBr}$ sample).

characteristic absorptions due to the amino group are clearly observed at $3300-3400 \mathrm{~cm}^{-1}$. Moreover, the absorption peak at $1288.2 \mathrm{~cm}^{-1}$ demonstrates the existence of aromatic thioether $(\phi-S-\phi)$ linkages in the diamine. The ${ }^{1} \mathrm{H}$ and ${ }^{13} \mathrm{C}$ NMR spectra, shown in Figure 2, further verify the structures. The ${ }^{1} \mathrm{H}$ NMR spectrum (Figure 2a) shows a signal assignable to amino protons at $5.39 \mathrm{ppm}$, and the ${ }^{13} \mathrm{C}$ NMR spectrum (Figure 2b) exhibits six signals due to the symmetry of molecular structure. The ${ }^{1} \mathrm{H}$ and ${ }^{13} \mathrm{C}$ chemical shifts are in good agreement with the expected values for the diamine. The structure was also confirmed by the elemental analysis.

\section{Polyimide Synthesis}

The synthesis of PIs was conducted in NMP as shown in Scheme 2. First, PAA precursors with the inherent viscosities of $0.62-1.17 \mathrm{dL} / \mathrm{g}$ were prepared by the polycondensation of 2SPDA with aromatic tetracarboxylic dianhydrides at room temperature 


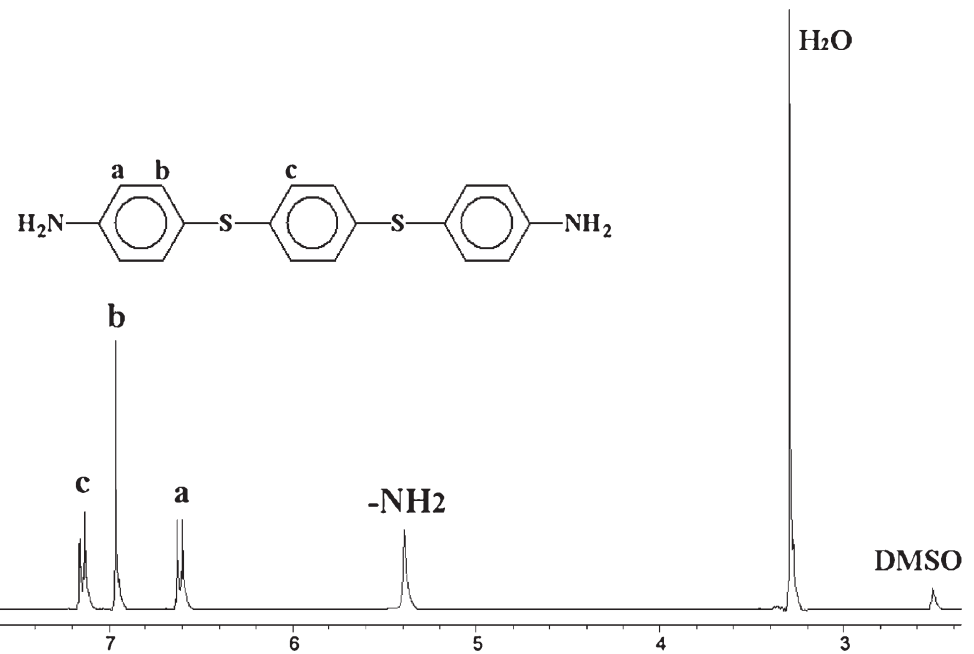

(a)
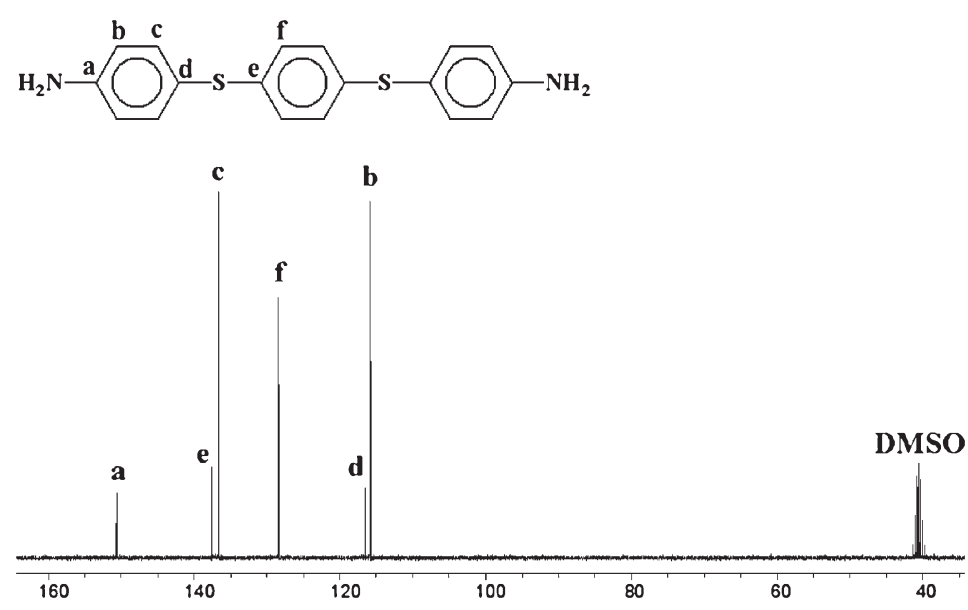

(b)

Figure 2. ${ }^{1} \mathrm{H}$ NMR (a) and ${ }^{13} \mathrm{C}$ NMR (b) of $2 \mathrm{SPDA}$ (DMSO- $d_{6}, 300 \mathrm{MHz}$ ).

(Table I). Flexible and tough PI films were obtained from their PAA precursors, indicating high molecular weights of PIs. The results of elemental analysis summarized in Table I indicate that the elemental compositions of the PIs agree well with the expected ones. The coloration of the films varies from pale yellow (PI-3) to brown (PI-1) at the thickness of $30-50 \mu \mathrm{m}$, suggesting that partial oxidization and degradation occurred during thermal imidization. Thus, the films prepared under nitrogen were used for optical measurements. The coloration was obviously decreased by this treatment. Figure 3 presents the FT-IR spectra of PI films. The similar spectra reveal the characteristic absorptions to the imide moiety at $1780 \mathrm{~cm}^{-1}$ $\left(v_{\mathrm{asC}=\mathrm{O}}\right), 1720 \mathrm{~cm}^{-1}\left(v_{\mathrm{s}} \mathrm{C}=\mathrm{O}\right)$, and $1380 \mathrm{~cm}^{-1}\left(v_{\mathrm{C}-\mathrm{N}}\right)$, which supported the formation of PIs. Wide-angle $\mathrm{X}$-ray measurements showed that the resulting PIs are entirely amorphous polymers.

\section{Thermal Properties}

Polymer materials used for optical applications should possess sufficient thermal stability to withstand the prolonged periods of thermal fabrications or environmental tests. ${ }^{28}$ Figure 4 and Table II show the TGA curves and thermal decomposition data for the PIs, respectively. The synthesized PIs possess good thermal stability with the $5 \%$ and $10 \%$ weight loss temperatures at $509-537^{\circ} \mathrm{C}$ and $529-553^{\circ} \mathrm{C}$, respectively. In addition, the polyimide films maintained more than $80 \%$ of their original weights at $550{ }^{\circ} \mathrm{C}$. The DSC curves, depicted in Figure 5, demonstrate that the glass transition temperatures $\left(T_{\mathrm{g}}\right)$ of the PIs are in the range of $214.6-261.6^{\circ} \mathrm{C}$. PI-1, derived from sBPDA and 2SPDA exhibit the highest thermal stability, whereas PI-3, derived from ODPA and 2SPDA, shows the lowest one. This trend is consistent with their chemical structures. PI-3 includes flexible and less-stable ether or thioether linkages in the dianhydride and diamine moieties. In addition, the flexible molecular chains due to thioether linkages undergo vigorous molecular motion under elevated temperatures, resulting in the obvious decrease in $T_{\mathrm{g}}$. 


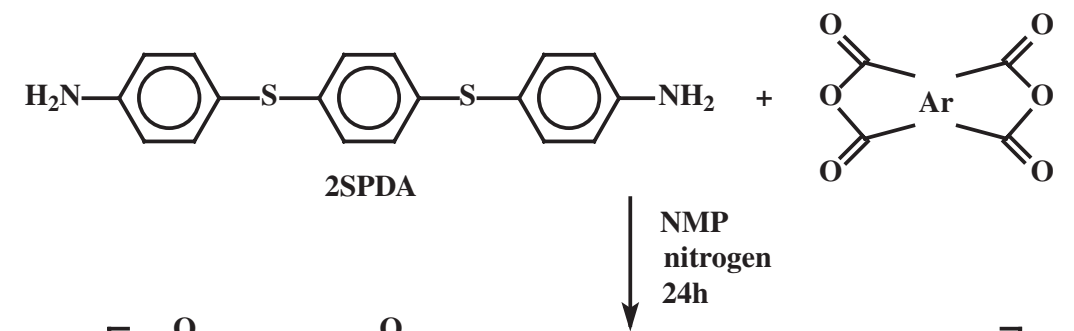<smiles>Cc1ccc(Sc2ccc(Sc3ccc(NC(=O)C4CCCCC4(C)C)cc3)cc2)cc1</smiles>

PAA<smiles>CCC(C)(C)c1ccc(Sc2ccc(Sc3ccc(N4C(=O)[I-]56CC4COC5C6)cc3)cc2)cc1</smiles>

PI

Ar:

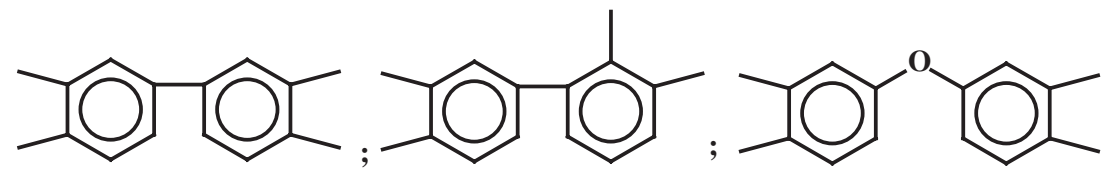

SBPDA, PI-1

aBPDA, PI-2

ODPA, PI-3

Scheme 2. Synthesis of PIs.

Table I. Synthesis and characterizations of polyimides

\begin{tabular}{|c|c|c|c|c|c|c|}
\hline \multirow{2}{*}{ PI } & \multirow{2}{*}{$\begin{array}{l}{[\eta]_{\text {inh }}{ }^{\mathrm{a}}} \\
(\mathrm{dL} / \mathrm{g})\end{array}$} & \multirow{2}{*}{$\begin{array}{l}\text { Film } \\
\text { quality }^{\mathrm{b}}\end{array}$} & \multicolumn{4}{|c|}{ Elemental analysis } \\
\hline & & & & $\mathrm{C}(\%)$ & $\mathrm{H}(\%)$ & $\mathrm{N}(\%)$ \\
\hline \multirow{2}{*}{ PI-1 } & \multirow{2}{*}{1.17} & \multirow{2}{*}{$\mathrm{F}, \mathrm{T}$} & Calcd & 70.09 & 3.11 & 4.81 \\
\hline & & & Found & 69.25 & 3.37 & 4.46 \\
\hline \multirow{2}{*}{ PI-2 } & \multirow{2}{*}{0.62} & \multirow{2}{*}{$\mathrm{F}, \mathrm{T}$} & Calcd & 70.09 & 3.11 & 4.81 \\
\hline & & & Found & 69.17 & 3.28 & 4.31 \\
\hline \multirow{2}{*}{ PI-3 } & \multirow{2}{*}{0.76} & \multirow{2}{*}{$\mathrm{F}, \mathrm{T}$} & Calcd & 68.22 & 3.03 & 4.68 \\
\hline & & & Found & 67.89 & 3.14 & 4.33 \\
\hline
\end{tabular}

${ }^{a}$ Measured with PAA at a concentration of $0.5 \mathrm{~g} / \mathrm{dL}$ of NMP solution at $30{ }^{\circ} \mathrm{C}$. ${ }^{\mathrm{b}} \mathrm{F}$ : flexible; T: tough.

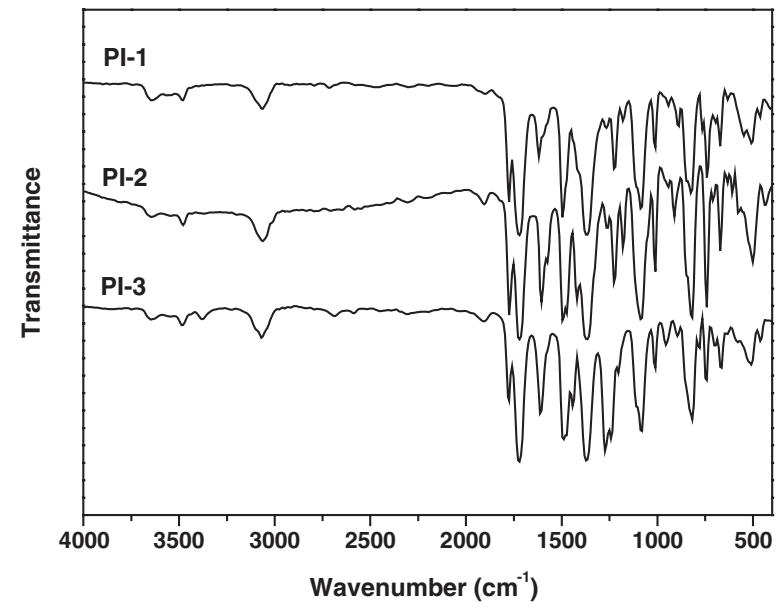

Figure 3. FT-IR spectra of PI films (film samples).

Table II. Thermal properties of the polyimides

\begin{tabular}{|c|c|c|c|c|c|c|c|}
\hline \multirow{2}{*}{ PI } & \multicolumn{2}{|c|}{$T_{\mathrm{g}}\left({ }^{\circ} \mathrm{C}\right)^{\mathrm{a}}$} & \multirow{2}{*}{$\begin{array}{l}T_{5 \%}{ }^{\mathrm{a}} \\
\left({ }^{\circ} \mathrm{C}\right)\end{array}$} & \multirow{2}{*}{$\begin{array}{c}T_{10 \%}{ }^{\mathrm{a}} \\
\left({ }^{\circ} \mathrm{C}\right)\end{array}$} & \multirow{2}{*}{$\begin{array}{c}R_{\mathrm{w} 550^{\mathrm{a}}} \\
\quad(\%)\end{array}$} & \multirow{2}{*}{$\begin{array}{c}E^{\prime \mathrm{a}} \\
(\mathrm{GPa})\end{array}$} & \multirow{2}{*}{$\begin{array}{c}E^{\prime \prime \mathrm{a}} \\
(\mathrm{MPa})\end{array}$} \\
\hline & DSC & DMA & & & & & \\
\hline PI-1 & 261.6 & 247.0 & 537 & 553 & 91 & 2.78 & 81.3 \\
\hline PI-2 & 246.5 & 230.5 & 528 & 540 & 83 & 3.55 & 125.9 \\
\hline PI-3 & 214.6 & 222.5 & 509 & 529 & 83 & 2.80 & 106.3 \\
\hline
\end{tabular}

${ }^{\mathrm{a}} T_{\mathrm{g}}$ : Glass transition temperatures; $T_{5 \%}, T_{10 \%}$ : Temperatures at $5 \%$ and $10 \%$ weight loss, respectively; $R_{\mathrm{w} 550}$ : Residual weight ratio at $550^{\circ} \mathrm{C} ; E^{\prime}$ : Storage modulus, $E^{\prime \prime}$ : Loss modulus, measured at $30^{\circ} \mathrm{C}, 1 \mathrm{~Hz}$. 


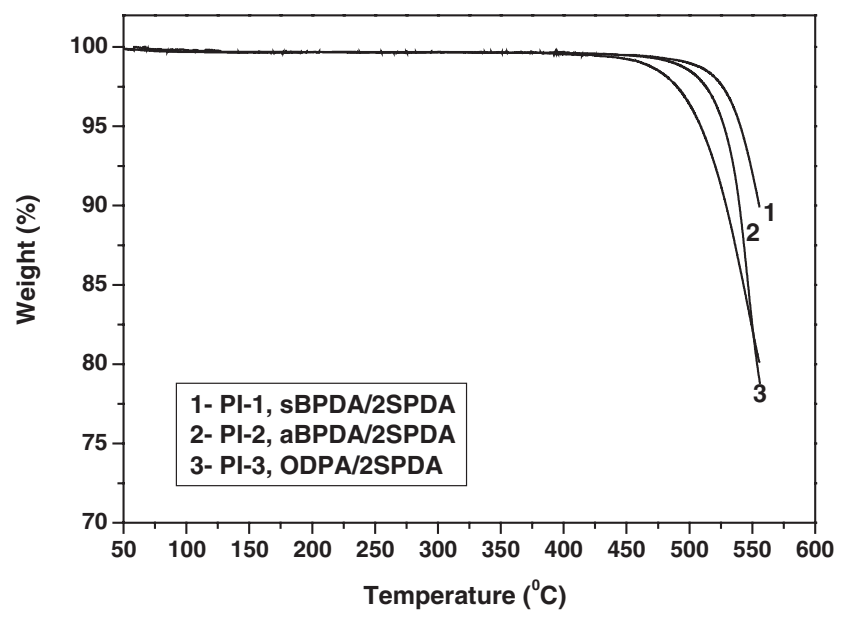

Figure 4. TGA curves of polyimides (in nitrogen, $10^{\circ} \mathrm{C} / \mathrm{min}$ ).

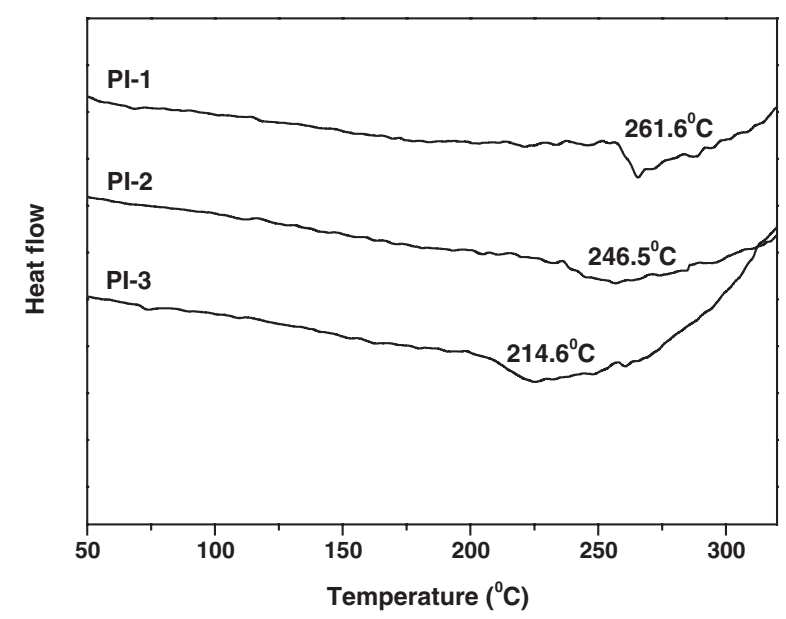

Figure 5. DSC curves of polyimides (in nitrogen, $10^{\circ} \mathrm{C} / \mathrm{min}$ ).

Figure 6 shows the typical DMA curves of the PIs measured at the loading frequency of $1 \mathrm{~Hz}$. The relationships between the temperatures and the storage modulus $\left(E^{\prime}\right)$, loss modulus $\left(E^{\prime \prime}\right)$, and $\tan \delta$ of the polymers are illustrated, respectively. The polymers retain their mechanical properties up to about $250^{\circ} \mathrm{C}$ for PI-1, $230^{\circ} \mathrm{C}$ for PI-2, and $220^{\circ} \mathrm{C}$ for PI-3. The modulus of the polymers dropped dramatically at $T_{\mathrm{g}}$. Generally, the $T_{\mathrm{g}}$ values are determined as the peak temperatures of the $E^{\prime \prime}$ plots. Thus, PI-1 shows the $T_{\mathrm{g}}$ of $247.0^{\circ} \mathrm{C}$, which is $14.6^{\circ} \mathrm{C}$ lower than that measured by DSC. However, PI-3 shows the $T_{\mathrm{g}}$ value of $222.5^{\circ} \mathrm{C}$ in DMA measurement, which was about $8^{\circ} \mathrm{C}$ higher than that determined by DSC. The difference is attributed to the different testing techniques, and the different responses of the polymers to calorimetric (DSC) and dynamic-mechanical (DMA) measurements. The polymers show the initial storage modulus of $2.78 \mathrm{GPa}$ for PI-1, 3.55 GPa for PI-2, and $2.80 \mathrm{GPa}$ for PI-3, indicating the good mechanical properties of the polymers.

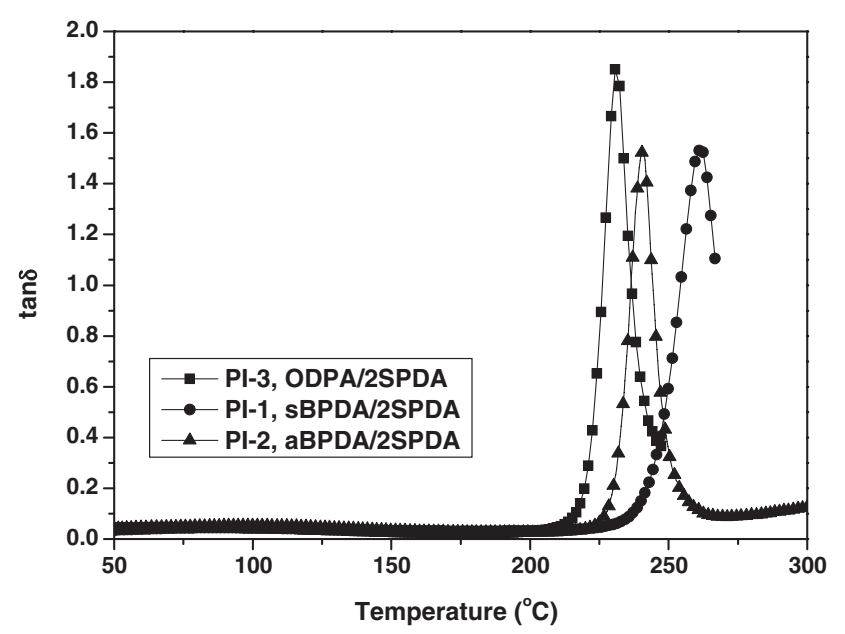

(a)

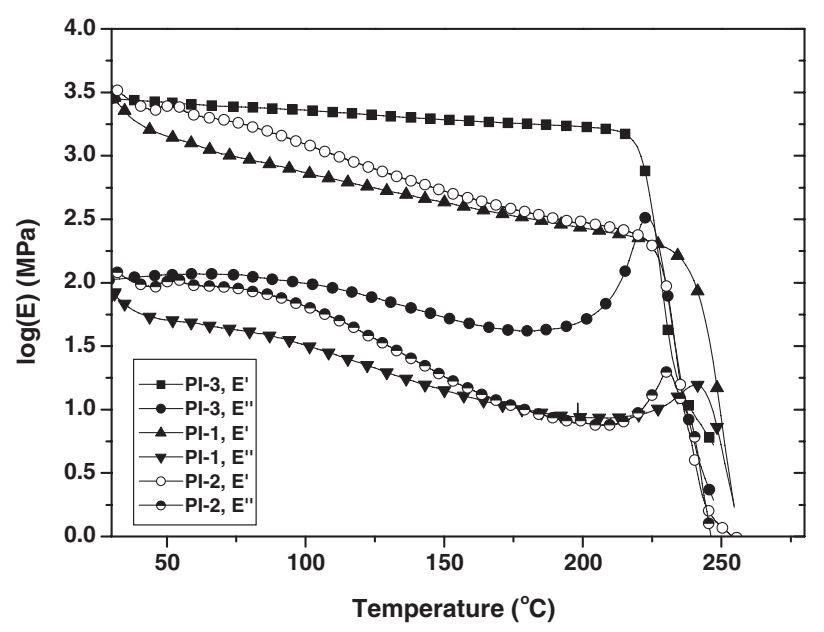

(b)

Figure 6. DMA curves PIs (a) $\tan \delta$, (b) storage modulus $E^{\prime}$ and loss modulus of $E^{\prime \prime}$ (in air, $2{ }^{\circ} \mathrm{C} / \mathrm{min}$ ).

\section{Optical Properties}

The optical properties of the PI films, evaluated by UV-Vis spectra (Figure 7) and DFT calculations are summarized in Table III. It could be seen from Figure 7 that the PI films show good transparency with higher than $80 \%$ at $500 \mathrm{~nm}$. All the films exhibit better optical transparency than that of the standard aromatic PI, derived from pyromellitic dianhydride (PMDA) and 4,4'-oxydianiline (ODA) at the similar thickness. Clear trends can be found between the sulfur contents and the optical properties of the PI films. For example, PI-1, with the higher sulfur contents, exhibits the longest cutoff wavelength $(397 \mathrm{~nm})$, the lowest transmittance at $500 \mathrm{~nm}(81.3 \%)$, and the highest $n_{\mathrm{av}}$ (1.7356). PI-2, derived from aBPDA and 2SPDA exhibits the second highest $n_{\mathrm{av}}$ of 1.7183, which is 0.0173 lower than that of PI- 1 despite the same sulfur content (Figure 8). This result indicated that sulfur content is the crucial factors to affect the refractive index of the polymers, but not the only 


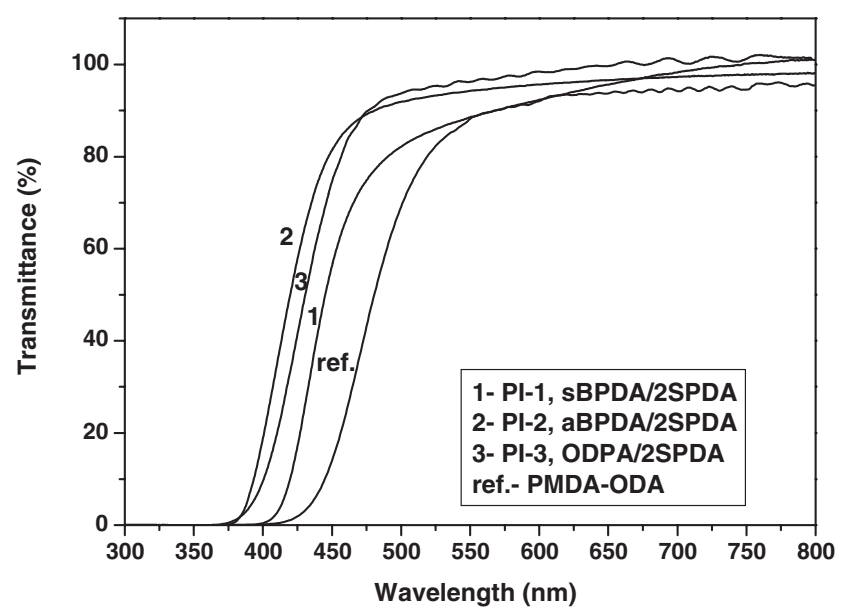

Figure 7. UV-Vis spectra of PI films (film thickness: $\sim 10$ $\mu \mathrm{m})$.

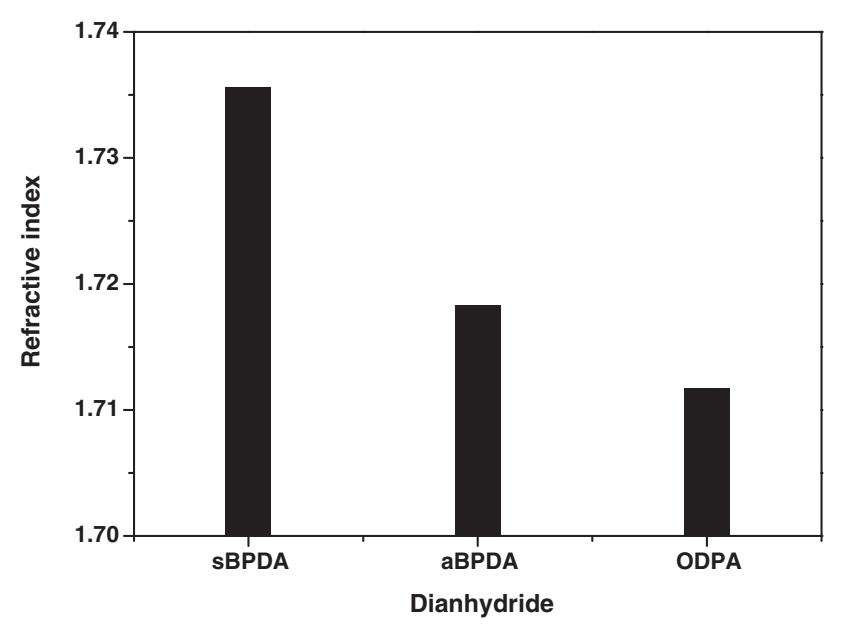

Figure 8. Refractive indices of the polyimide films $(632.8$ $\mathrm{nm})$.

Table III. Refractive indices of the polyimides

\begin{tabular}{|c|c|c|c|c|c|c|c|c|c|}
\hline \multirow{2}{*}{ PI } & \multirow{2}{*}{$\begin{array}{l}S_{\mathrm{C}}{ }^{\mathrm{a}} \\
(\%)\end{array}$} & \multirow{2}{*}{$\begin{array}{c}\lambda_{\text {cutoff }}{ }^{\mathrm{b}} \\
(\mathrm{nm})\end{array}$} & \multirow{2}{*}{$\begin{array}{c}T_{500}{ }^{\mathrm{b}} \\
(\%)\end{array}$} & \multirow{2}{*}{$\begin{array}{c}d^{\mathrm{c}} \\
(\mu \mathrm{m})\end{array}$} & \multicolumn{4}{|c|}{ Refractive indices at $632.8 \mathrm{~nm}$} & \multirow{2}{*}{$n_{\mathrm{cal}}{ }^{\mathrm{e}}$} \\
\hline & & & & & $n_{\mathrm{TE}}^{\mathrm{d}}$ & $n_{\mathrm{TM}}^{\mathrm{d}}$ & $\Delta n^{\mathrm{d}}$ & $n_{\mathrm{av}}{ }^{\mathrm{d}}$ & \\
\hline PI-1 & 11.00 & 397 & 81.3 & 7.8 & 1.7396 & 1.7277 & 0.0119 & 1.7356 & 1.7260 \\
\hline PI-2 & 11.00 & 376 & 91.2 & 6.1 & 1.7208 & 1.7133 & 0.0074 & 1.7183 & 1.7260 \\
\hline PI-3 & 10.77 & 373 & 93.4 & 9.8 & 1.7151 & 1.7047 & 0.0104 & 1.7117 & 1.7110 \\
\hline ref & 0 & 415 & 69.1 & 9.2 & - & - & $0.0780^{\mathrm{f}}$ & $1.6950^{\mathrm{f}}$ & - \\
\hline
\end{tabular}

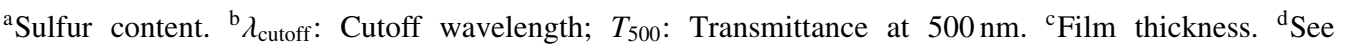
Measurements. ${ }^{\mathrm{e}} \mathrm{See}$ Calculations. ${ }^{\mathrm{f}}$ reference 30.

one. The solid state structures of PIs including chain rigidity and degree of molecular packing reflected on density, should affect the refractive index to some extent. The fact that the $n_{\text {av }}$ value for PI-2 is significantly lower than that for the isometric PI-1 clearly indicates the asymmetric dianhydride moiety in PI-2 causes a lowering of molecular packing, leading to the reduction of $n_{\mathrm{av}}$. Actually, the loose molecular packing of aBPDA-based PIs has been reported in the literature. ${ }^{29}$ The identical values of calculated refractive indices for PI-1 and PI-2 also support this view. Further, the lowest $n_{\mathrm{av}}$ observed for PI-3 (1.7117) in the three PIs agrees well with the calculated value, which is due to the lowest sulfur content and the absence of specific intermolecular interactions leading to dense molecular packing. It should also be noticed that the refractive index values of the present PIs are higher than that of PMDA-ODA $(1.6950),{ }^{30}$ which are mainly attributed to the introduction of sulfur groups in the present PIs.

The values of in-plane/out-of-plane birefringence $(\Delta n)$ of the PIs are in the range of 0.0074-0.0119, which are quite lower than that of PMDA-ODA (0.078). Such small birefringence can readily be attributed to both of the small polarizability anisotropy and the low degree of molecular orientation due to the flexible thioether linkages in the molecular chains. $^{31}$

The dielectric constants of the PI films can be roughly estimated from the refractive indices using the modified Maxwell equation: $\varepsilon=1.10 n_{\mathrm{av}}{ }^{2},{ }^{32}$ where $\varepsilon$ is the dielectric constant at around $1 \mathrm{MHz}$. Thus, the estimated $\varepsilon$ values are $3.31,3.25$, and 3.22 for PI-1, PI-2, and PI-3, respectively, which are the typical values for wholly aromatic polyimides.

\section{CONCLUSIONS}

Sulfur-containing PIs with good combined properties, including the high thermal stability, good optical transparency in the visible light region, high refractive indices, and low birefringence, have been successfully prepared from a newly prepared aromatic diamine 2SPDA and several aromatic tetracarboxylic dianhydrides. The PI films demonstrate the refractive indices of higher than 1.71 and the birefringence of smaller than 0.012 , indicating that the introduction of thioether moieties in the main chains is effective to increase the refractive indices with decreasing the birefringence. The good combined properties of the PIs make them good candidates for thermally stable polymers applicable to advanced optical applications. 
Acknowledgment. The financial support from the Japan Synthetic Rubber Corporation for this work is gratefully acknowledged.

\section{REFERENCES}

1. "Polyimides Fundamentals and Applications," M. K. Ghosh and K. L. Mittal, Ed., Marcel Dekker, New York, 1996.

2. M. Hasegawa and K. Horie, Prog. Polym. Sci., 26, 259 (2001).

3. B. G. Prevo, Y. Hwang, and O. D. Velev, Chem. Mater., 17, 3642 (2005).

4. S. H. Baek, J. W. Kang, X. D. Li, M. H. Lee, and J. J. Kim, Opt. Lett., 29, 301 (2004).

5. N. Yurt, K. Mune, R. Naito, T. Fukuoka, A. Mochizuki, K. Matsomoto, G. Meredith, N. Peyghambarian, and G. E. Jabbour, J. Lightwave Technol., 23, 1291 (2005).

6. S. I. Matsuda, Y. Urano, J. W. Park, C. S. Ha, and S. Ando, J. Photopolym. Sci. Technol., 17, 241 (2004).

7. S. Ando, T. Matsuura, and S. Sasaki, Macromolecules, 25, 5858 (1992).

8. S. Ando, T. Sawada, and S. Sasaki, Polym. Adv. Technol., 10, 169 (1999).

9. C. Cornic, B. Lucas, A. Moliton, B. Colombeau, and R. Mercier, Synth. Met., 127, 299 (2002).

10. Y. Terui and S. Ando, J. Photopolym. Sci. Technol., 18, 337 (2005)

11. R. M. L. Mercado and W. L. Dimenna, U.S. Patent 2005065278 (2005), Chem. Abstr., 142, 317546 (2006).

12. T. Matsuda, Y. Funae, M. Yoshida, and T. Yamamoto, J. Macromol. Sci., Part A: Pure Appl. Chem., 37, 239 (2000).

13. T. Matsuda, Y. Funae, M. Yoshida, T. Yamamoto, and T. Takaya, J. Appl. Polym. Sci., 76, 45 (2000).
14. T. Matsuda, Y. Funae, M. Yoshida, T. Yamamoto, and T. Takaya, J. Appl. Polym. Sci., 76, 50 (2000).

15. C. L. Lu, Z. C. Cui, Y. X. Wang, B. Yang, and J. C. Shen, J. Appl. Polym. Sci., 89, 2426 (2003).

16. K. Okazaki, Y. Kanemura, and T. Nagata, Eur. Patent 0665219 (1995), Chem. Abstr., 123, 288986 (1996).

17. K. Okazaki, Y. Kanemura, and T. Nagata, Eur. Patent 0676428 (1995), Chem. Abstr., 124, 31110 (1996).

18. T. Flaim, Y. B. Wang, and R. Mercado, SPIE Proc., 5250, 423 (2004).

19. J. Nakai and T. Aoki, U.S. Patent 2004142501 (2004), Chem. Abstr., 141, 132593 (2005).

20. M. Suwa, H. Niwa, and M. Tomikawa, J. Photopolym. Sci. Technol., 19, 275 (2006).

21. I. Rozhanskii, K. Okuyama, and K. Goto, Polymer, 41, 7057 (2000).

22. Y. Terui and S. Ando, J. Polym. Sci., Part B: Polym. Phys., 42, 2354 (2004).

23. H. A. Lorentz, Ann. Physik Chemie, 9, 641 (1880).

24. L. Lorenz, Ann. Physik Chemie, 11, 70 (1880).

25. G. Slonimskii, A. Askadskii, and A. Kitaigodorodskii, Polym. Sci. USSR, A12, 556 (1970).

26. A. Bondi, J. Phys. Chem., 68, 441, (1964).

27. Y. Terui and S. Ando, J. Photopolym. Sci. Technol., 18, 337 (2005).

28. G. Maier, Prog. Polym. Sci., 26, 3 (2001).

29. C. P. Yang and Y. Y. Su, Polymer, 46, 5797 (2005).

30. T. P. Russel, H. Gugger, and J. D. Swalen, J. Polym. Sci., Polym. Phys. Ed., 21, 1745 (1983).

31. C. Badara and Z. Y. Wang, Macromolecules, 37, 147 (2004).

32. D. Boese, H. Lee, D. Y. Yoon, J. D. Swalen, and J. F. Rabolt, J. Polym. Sci., Part B: Polym. Phys., 30, 1321 (1992). 